\title{
Validation of AD8-Philippines (AD8-P): A Brief Informant-Based Questionnaire for Dementia Screening in the Philippines
}

\author{
Jacqueline C. Dominguez $\mathbb{D}^{1,2,3}$ Ma. Fe P. de Guzman, ${ }^{2,3,4}$ Ma. Lourdes C. Joson $\mathbb{D}^{1,3,5}$ \\ Krizelle Fowler, ${ }^{2,3,4}$ Boots P. Natividad, ${ }^{2,4}$ Precy S. Cruz, ${ }^{2,3}$ Jose Leo Jiloca, ${ }^{2,3,6}$ \\ Primitivo B. Mactal Jr., ${ }^{1,3}$ Jayvee Dyne Dominguez, ${ }^{2,7}$ Jeffrey Domingo, ${ }^{2,7}$ \\ Jhozel Kim Dominguez-Awao, ${ }^{2,8}$ Macario Reandelar Jr., ${ }^{4}$ Jem R. Javier, \\ ThienKieuThi Phung, ${ }^{10}$ John C. Morris, ${ }^{11}$ and James E. Galvin ${ }^{12}$ \\ ${ }^{1}$ Institute for Neurosciences, St. Luke's Medical Center, Quezon City 1102, Philippines \\ ${ }^{2}$ Institute for Dementia Care Asia, Quezon City 1102, Philippines \\ ${ }^{3}$ Dementia Society of the Philippines, Manila City 1008, Philippines \\ ${ }^{4}$ Research and Biotechnology Division, St. Luke's Medical Center, Quezon City 1102, Philippines \\ ${ }^{5}$ Department of Neuroscience and Behavioral Medicine, Faculty of Medicine and Surgery, University of Santo Tomas, \\ Manila 1008, Philippines \\ ${ }^{6}$ Geriatric Center, St. Luke's Medical Center, Quezon City 1102, Philippines \\ ${ }^{7}$ St. Luke's College of Medicine William H. Quasha Memorial, Quezon City 1102, Philippines \\ ${ }^{8}$ St. Louis University College of Medicine, Baguio City 2600, Philippines \\ ${ }^{9}$ Department of Linguistics, College of Social Sciences and Philosophy, University of the Philippines, Quezon City 1100, Philippines \\ ${ }^{10}$ Department of Neurology, Danish Dementia Research Center, Rigshospitalet, University of Copenhagen, \\ Copenhagen 2100, Denmark \\ ${ }^{11}$ Department of Neurology, Washington University School of Medicine, St. Louis, MO, USA \\ ${ }^{12}$ Comprehensive Center for Brain Health, Department of Neurology, University of Miami Miller School of Medicine, USA
}

Correspondence should be addressed to Ma. Lourdes C. Joson; mcjoson@ust.edu.ph

Received 19 June 2021; Accepted 6 October 2021; Published 31 October 2021

Academic Editor: John Powell

Copyright (c) 2021 Jacqueline C. Dominguez et al. This is an open access article distributed under the Creative Commons Attribution License, which permits unrestricted use, distribution, and reproduction in any medium, provided the original work is properly cited.

\footnotetext{
Aim. This study was aimed at validating the Filipino version of AD8 (AD8-P). Methods. Community-dwelling Filipino older persons aged $\geq 60$ years, together with their informants, participated in this study. Psychologists independently interviewed the informants with AD8-P and administered the Filipino-validated Mini-Mental State Examination (MMSE-P) and Montreal Cognitive Assessment (MoCA-P) to the older persons. Neurologists and geriatrician conducted physical and neurological examination and Clinical Dementia Rating ${ }^{\mathrm{TM}}\left(\mathrm{CDR}^{\mathrm{TM}}\right)$ to determine cognitive diagnosis and were blinded with the results of AD8-P. Dementia was diagnosed based on DSM-IV-TR criteria. AD8-P discriminatory ability to screen for dementia was evaluated according to DSM-IV-TR diagnostic criteria for dementia. Results. A total of 366 community-dwelling Filipino older persons aged $\geq 60$ years, 213 with normal cognition and 153 with dementia, and their informants were included in this study. Majority (90\%) were at the mildest stage of dementia. Area under the receiver-operating-characteristic curve (AUROC) for AD8-P was 0.94 (95\% CI 0.92 to 0.96), demonstrating excellent overall predictive power to screen for dementia. The optimal AD8-P cut-off score with best balance sensitivity (91.5\%) and specificity (77.9\%) was $\geq 3$. Conclusion. AD8-P demonstrated good psychometric properties to screen for dementia, even at the earliest stage of cognitive decline.
} 


\section{Introduction}

Dementia is a major cause of disability and dependency among older adults worldwide. The number of older persons living with dementia is steadily increasing and projected to reach as high as 131.5 million by 2050 [1]. In the Philippines, the prevalence of dementia was found to be $10.6 \%$ among older Filipino adults aged 60 and above [2], a proportion which is higher than the estimated $7.6 \%$ prevalence for South East Asia [1]. Despite this growing public health problem, screening and detection for dementia remain a major challenge. High prevalence of undetected dementia in the community is estimated to be $93 \%$ in Asia and between 43 and $71 \%$ in Europe and North America [3]. The causes of missed or delayed diagnosis for dementia include case complexity, resource constraints, lack of awareness, and lack of culture-sensitive and education-fair instruments for dementia screening [4]. Commonly used screening instruments for dementia in the Philippines include the Filipino-validated Mini-Mental State Examination (MMSE-P) [5] and the Montreal Cognitive Assessment (MoCA-P) [6, 7]. Both tests are strictly standardized and require training to administer and interpret. Moreover, the scores on both tests are strongly influenced by educational and other sociocultural factors $[8,9]$.

In the context of Asian countries where extended family structure still prevails, informant-based assessments have been demonstrated to be superior to direct cognitive testing in screening for dementia and detecting early signs of cognitive impairment $[10,11]$. The consensus today is that patient- and informant-based questionnaire should be combined to enhance screening and diagnostic accuracy [12]. Informant-based assessments minimize biases such as practice effects, low education, and sociocultural influences, which confound the interpretation of direct cognitive assessments [13]. The most commonly used research assessments that incorporate information from informants to evaluate patients' cognitive ability are the Clinical Dementia Rating ${ }^{\mathrm{TM}}$ $\left(\mathrm{CDR}^{\mathrm{TM}}\right)$ and the Informant Questionnaire for Cognitive Decline in the Elderly (IQCODE) [14, 15]. Both assessments have demonstrated good psychometric properties to distinguish between dementia and normal cognition [14-16]. The IQCODE has been validated in developing countries with high rates of illiteracy, demonstrating excellent discriminating power to screen for dementia in this context $[17,18]$. However, both instruments are not suitable to be used for dementia screening in the community in the Philippines. The CDR is lengthy and complex to administer, a task usually done by an experienced clinician, usually a dementia specialist. The IQCODE requires the informant to rate the cognitive function of the older person using five graded categories of change (much improved, somewhat improved, no change, somewhat worse, and much worse). The differences between these categories have been found to be indistinguishable for Filipinos. A study to validate the IQCODE in Tagalog demonstrated that the participants found it impossible to quantify the degree of change between "much" and "somewhat" (Dominguez J, data unpublished). Further, the IQCODE may not discriminate normal aging from mild cognitive impairment [19]. The $\left(\mathrm{AD}^{\mathrm{TM}}\right)$ is a brief informant-based screening instrument for dementia developed by the Alzheimer's Disease Research Center, Washington University in St. Louis [20, 21]. Compared with other informant-based assessments, AD8 has been shown to be more sensitive to capture the early stages of dementia [19], regardless of the etiologies [20,21], and corresponds to Alzheimer biomarkers [22]. The AD8 is designed to capture a decline from previous levels for an individual's cognitive and functional performance (intraindividual change), which is the sine qua non for dementia detection; the MMSE and MoCA cannot capture such decline unless administered longitudinally. Hence, the AD8 may offer this advantage over those instruments for dementia screening. In addition, all of the AD8 questions come from the informant interview of the CDR and AD8 is considered an abbreviated CDR interview; thus, the correspondence between the AD8 and the CDR should be very high. The AD8 has been validated with molecular biomarkers and neuropathologic diagnosis of Alzheimer's disease facilitating earlier and more accurate $\mathrm{AD}$ diagnosis in a variety of care settings [23].

The administration of AD8 requires minimal training and can be easily conducted in person or through phone calls within three minutes [20], making it particularly suitable for dementia screening in the community setting and primary care. The answers are simple (yes, no, and not applicable) and can also be self-administered by the informant [24]. In the absence of a reliable informant, the AD8 may be asked of the participant to gain an understanding of their perception of cognitive status [24]. The AD8 rates decline that can be ascribed to the cognitive loss but not due to other causes (e.g., significant visual impairment limits the ability to drive would not merit a "yes" response on the AD8).

Therefore, this study was aimed at validating the Filipino version of the AD8 (AD8-P) in screening for dementia among community-dwelling Filipino older adults.

\section{Materials and Methods}

2.1. Study Design and Population. Participants were community-dwelling Filipino older adults enrolled in the Marikina Memory and Aging Project (MMAP), which was a large population-based longitudinal study of dementia epidemiology in the community [2]. The cohort was established in 2011-2012 and consisted of a random sample of 1,367 participants $\geq 60$ years old who were selected from the senior citizen registry in the city of Marikina [2]. We established the prevalence of dementia and cognitive impairment nondementia (CIND) in this cohort in 2011 and followed them up in 2016-2017 (5-year followup), when there were $831(60.8 \%)$ participants left in the cohort. The study population for this validation study was selected from this follow-up cohort. We carried out comprehensive cognitive assessments of the whole cohort to identify persons with dementia and normal cognition. The study was approved by the St. Luke's Institutional Ethics Review Committee (CT-14064). 
2.2. Eligibility Criteria. The eligibility criteria were as follows: (1) community-dwelling Filipinos aged $\geq 60$ years old, (2) diagnosed with dementia according to DSM-IV TR criteria [25] and $\mathrm{CDR} \geq 0.5$ or with normal cognition $(\mathrm{CDR}=0)$ [15], (3) were fluent in Tagalog, and (4) had an available informant. An informant was defined as the person who knew the participant well or coresides with the participant for at least a year, such as a relative, a friend, a neighbor, or a caregiver.

2.3. Translation of AD8-P. To construct the Filipino version of AD8 (AD8-P), a direct translation of the original AD8 was carried out by two Filipino bilingual experts, a neurologist (SM) and a psychologist (PM). English and Filipino are the two main official languages of the Philippines, a country where 170 different languages are spoken. The translation was reviewed and backtranslated by another psychologist and a specialist in linguistics (JJ). The Filipino version was subsequently reviewed by multidisciplinary committee from Dementia Society of the Philippines composed of neurologists, geriatricians, psychologists, nurses, and linguists led by $\mathrm{SM}$ and $\mathrm{PC}$ to evaluate the semantic and conceptual equivalence of each item in the AD8 questionnaire. The translation and backtranslation underwent 3 iterations until the final version. Some examples in the original English version were modified to be relevant to the Filipino context.

In question 4, regarding trouble learning how to use a tool, appliance, or gadget, the "VCR" example was changed to "VCD," which was a more relevant appliance in a Filipino household at that time. Likewise, use of computer and microwave amongst the Filipino elderly was not common; thus, these were replaced with cellular phone, television, or karaoke.

The translated AD8-P questionnaire was administered to five Filipino older adults to examine the face validity of the questionnaire and was found easy to understand and useful by the informants. The translated work was approved by the author of the AD8, Dr. James E. Galvin (JEG). Washington University in St. Louis, MO, granted license to the Dementia Society of the Philippines to lead the translation and validation.

2.4. Evaluation Procedure. Two community health workers provided by the city government of Marikina visited the older persons at home and coordinated their scheduled visits at the research site accompanied by their informants. The evaluation was carried out by well-trained psychologists (MDG, HSS, RLC, and CP), a geriatrician (JLJ), and neurologists (JCD, MCJ). AD8-P was administered by trained medical interns (JDD, JD, and JKD). Both the selected older persons and their informant participated in the assessments.

The psychologists independently administered the following assessments:

(A) To the informants

(i) Filipino version of AD8 (AD8-P): similar to the original English version [20], the AD8-P consists of 8 items that inquire into cognitive domains such as memory (frequent problems in memory, repetition, and remembering appointments), temporal orientation (trouble with month or year), judgment (making decision, handling finances), and function (reduced interest in activities, use of appliances). The score ranges from 0 to 8 , with higher scores indicating worse cognitive function

(ii) Lawton's Scale for Instrumental Activities of Daily Living (IADL) [26]: it is a functional scale to assess eight complex activities of daily living for the older person. The score ranges from 0 to 32 , lower scores indicating better functional levels

(B) To the older persons

(i) The Filipino-validated Mini-Mental State Examination (MMSE-P) [5]: MMSE measures orientation, attention, language, memory, and constructional praxis. In the Filipino MMSE$\mathrm{P}$, the serial subtraction was replaced with spelling backward a five-letter word (MUNDO or world in English). The score ranges from 0 to 30; lower score indicates worse cognitive function. The MMSE-P has demonstrated good psychometric properties to screen for dementia with a sensitivity of $85 \%$ and a specificity of $86 \%$ at the cut-off score of $\leq 23$ [5]

(ii) The Filipino-validated Montreal Cognitive Assessment (MoCA-P) [6, 7]: MoCA-P was designed as a screening instrument for mild cognitive dysfunction. It assesses different cognitive domains: attention and concentration, executive functions, memory, language, visuospatial functions, conceptual thinking, calculations, and orientation. The score ranges from 0 to 30 , with lower scores indicating worse $\operatorname{cog}$ nitive function. A MoCA-P cut-off of $\leq 20$ for dementia demonstrated psychometric property of $84 \%$ sensitivity and $72 \%$ specificity [6]

(iii) Geriatric Depression Scale (GDS) [27]: it is the most common scale currently used to measure depression in older adults. We used the brief version, the 15-item scale. A score of 5 or more indicates possible depression

The neurologists performed the following assessments:

(i) Clinical Dementia Rating ${ }^{\mathrm{TM}}$ [15]: the neurologist rated the CDR based on semistructured interview responses from the older persons and their informants. The CDR Sum of Boxes score is a total score ranging from 0 to 18 based on the sum of 6 domain scores (orientation, judgment and problem solving, memory, home and hobbies, personal care, and community affairs). Each domain is rated in five 
categories: normal (0), questionable or very mild dementia (0.5), mild dementia (1), moderate dementia (2), and severe dementia (3). These domains are then combined into a global CDR that ranges from 0 to 3

(ii) Physical and neurological examinations

2.5. Case Ascertainment. The neurologist (JCD, MJC) and geriatrician (JLJ) conducted medical history and physical examinations, CDR [15], and synthesized results of neuropsychological assessments, while being blinded to the result of AD8-P. All assessment data were reviewed by the physician, and they consulted with each other as necessary to reach a consensus on dementia diagnosis. Dementia was diagnosed according to DSM-IV TR criteria [25] and with CDR scores $\geq 0.5$. Participants were classified as having normal cognition and no depression if they had a $C D R=0$, did not fulfill DSM-IV TR criteria for dementia, and scored $\leq 4$ on GDS.

2.6. Statistical Analysis. Data analysis was performed using SPSS (version 23; IBM). Statistical tests were 2-tailed at significant level set at $p \leq 0.05$. The overall predictive ability of the AD8-P was evaluated using AUROC (area under the receiver operating characteristic curve, sensitivity plotted against 1 -specificity). The AUROC was used to choose the cut-off point with the best balance of sensitivity and specificity for the AD8-P. At the chosen cut-off point, the following parameters were estimated for the AD8-P: sensitivity, specificity, positive predictive value (PPV), negative predictive value (NPV), and Youden's index ( (sensitivity + specificity) -1 , summarizing sensitivity and specificity in a single measure). Chi-square test (or Fisher exact test when $\geq 20$ cells have expected count $<5$ ) to compare proportions. The Student $t$-test for independent samples was used to compare the means of age, education, and assessment scores between groups. To determine whether the older persons' characteristics (age, gender, and education) and the informants' characteristics (gender, age, education, and relationship to the older persons) affect the AD8-P scores, Student's $t$-test and one-way ANOVA were used to compare mean scores among the normative (reference) group. Pearson correlation coefficient $(r)$ was used to assess relationships between continuous variables.

\section{Results}

A total of 366 older persons and their informants were included in the study. The older persons' mean age was 73.4 (standard deviation or $\mathrm{SD}=6.97$ ) years old (range 63103 years), and the mean educational attainment was 9.1 $(\mathrm{SD}=4.12)$ years (range 0 to 18 years). Majority of the older persons $(69.9 \%)$ and their informants $(63.7 \%)$ were women. The informants were mainly children (44.0\%), spouses (38.9\%), grandchildren $(6.0 \%)$, and others such as daughters in law, siblings, neighbors, or close friends (11.1\%). Among the 366 older persons, $153(41.8 \%)$ had dementia and 213 (58.2\%) had normal cognition without depression (Table 1). Among those with dementia, 106 (69.3\%) had very mild dementia $(C D R=0.5), 32(20.9 \%)$ had mild dementia $(\mathrm{CDR}=1), 7 \quad(4.6 \%)$ had moderate dementia $(\mathrm{CDR}=2)$, and $8(5.2 \%)$ had severe dementia $(\mathrm{CDR}=3)$. Compared with those who were cognitively intact, older persons with dementia in this study had significantly higher age, lower education, and poorer performance on all neuropsychological and functional assessments (AD8, CDR-SB, MMSE-P, MoCA-P, and IADL, $p<0.001$, Table 1). For each AD8-P item, the group of older persons with dementia was rated significantly worse than those with normal cognition by the informants (Table 2).

The AD8-P demonstrated good internal consistency with a Cronbach alpha $(\alpha)$ of 0.82 (95\% confidence interval or $\mathrm{CI}, 0.79$ to 0.85 ). AD8-P scores were strongly correlated with scores from CDR-SB, MoCA-P, MMSE-P, and IADL (Table 3). The AUROC for the AD8-P was 0.94 (95\% CI, 0.92 to 0.96), demonstrating excellent overall predictive power to distinguish between normal cognition (CDR 0) and dementia (Figure 1). A cut-off score of $\geq 4$ has a good sensitivity (83.0\%) and an excellent specificity (90.6\%), whereas a cut-off score of $\geq 3$ has an excellent sensitivity (91.5\%) and a reasonable specificity (77.9\%). Since AD8-P was validated as a screening instrument for dementia, it is best to use the cut-off score with the highest sensitivity (Table 4).

AD8-P score is not affected by age, education, and gender of the older persons (Table 5). Concerning informant characteristics, AD8-P score is not affected by age and education of the informants and type of relationship to the older persons. However, female informants significantly rated higher score than male informant (Table 5). Subsequently, we did a sensitivity analysis of AUROC stratified by gender and found the AUROC was comparable for male and female informants, being 0.96 (95\% CI 0.92 to 0.99 ) for male and 0.91 (95\% CI 0.87 to 0.95 ) for female.

\section{Discussions}

We successfully validated a Filipino version of AD8 which is a brief informant-based questionnaire for dementia screening in the community. It has high internal consistency and strong correlation with other cognitive assessments such as the CDR-SB, MMSE, and MoCA, as well as functional assessment such as the IADL. Compared to the MMSE-P and MoCA-P [5, 6], AD8-P has better psychometric properties. At the cut-off point of $\geq 3, A D 8-P$ is more sensitive to detect dementia while maintaining similar specificity to MMSE-P and MoCA-P. This may be due to the fact that the AD8-P examines intraindividual decline rather than interindividual performance compared to a normative value. At the cut-off point of $\geq 4, \mathrm{AD} 8$-P has comparable sensitivity to MMSE-P and MoCA-P but with much higher specificity. Furthermore, AD8-P score is not affected by the older persons' age, gender, and education level, which makes AD8-P particularity suitable for dementia screening among older populations with low education. To our knowledge, this is the first study to examine whether informants' characteristics affect AD8-P score. We found that AD8-P is not affected by age and education level of the informant and the type of 
TABLE 1: Characteristics of study participants.

\begin{tabular}{|c|c|c|c|}
\hline & Normal cognition $(N=213)$ & Dementia $(N=153)$ & $p$ value \\
\hline \multicolumn{4}{|l|}{ Older persons' characteristics } \\
\hline \multicolumn{4}{|l|}{ Gender, $n(\%)$} \\
\hline Male & $70(32.9)$ & $40(26.1)$ & \multirow{2}{*}{0.17} \\
\hline Female & $143(67.1)$ & $113(73.9)$ & \\
\hline Age; M (SD) & $70.9(5.2)$ & $76.9(7.7)$ & $<0.001$ \\
\hline \multicolumn{4}{|l|}{ Age groups; $n(\%)$} \\
\hline 60-69 years old & $100(47.2)$ & $31(20.3)$ & \multirow{3}{*}{$<0.001$} \\
\hline 70-79 years old & $96(45.3)$ & $65(40.4)$ & \\
\hline$\geq 80$ years old & $16(7.5)$ & $57(37.3)$ & \\
\hline Education; $M(\mathrm{SD})$ & $10.8(3.4)$ & $6.9(4.0)$ & $<0.001$ \\
\hline \multicolumn{4}{|l|}{ Level of education; $n(\%)$} \\
\hline No formal education (0 year) & $1(0.5)$ & $11(7.2)$ & \multirow{4}{*}{$<0.001$} \\
\hline Primary education (1-6 years) & $35(16.4)$ & $85(55.6)$ & \\
\hline Secondary education (7-10 years) & $73(34.3)$ & $30(19.6)$ & \\
\hline Tertiary education ( $\geq 11$ years $)$ & $104(48.8)$ & $27(17.6)$ & \\
\hline \multicolumn{4}{|l|}{ Informants' characteristics } \\
\hline \multicolumn{4}{|l|}{ Relationship to the older person, $n(\%)$} \\
\hline Spouse & $101(47.4)$ & $43(28.1)$ & \multirow{4}{*}{$<0.005$} \\
\hline Child & $75(35.2)$ & $84(54.9)$ & \\
\hline Grandchild & $10(4.7)$ & $12(7.8)$ & \\
\hline Others & $27(12.7)$ & $14(9.2)$ & \\
\hline \multicolumn{4}{|l|}{ Gender, $n(\%)$} \\
\hline Male & $84(39.4)$ & $50(32.7)$ & \multirow{2}{*}{0.23} \\
\hline Female & $129(60.6)$ & $103(67.3)$ & \\
\hline Age; $M(\mathrm{SD})$ & $55.6(17.0)$ & $51.7(16.3)$ & 0.05 \\
\hline \multicolumn{4}{|l|}{ Age groups; $n(\%)$} \\
\hline 18-24 years old (young adult) & $11(5.2)$ & $7(4.6)$ & \multirow{3}{*}{0.02} \\
\hline 25-64 years old (midadult) & $111(52.1)$ & $104(68.0)$ & \\
\hline$\geq 65$ years old (older adult) & $91(42.7)$ & $42(27.4)$ & \\
\hline Education; $M(\mathrm{SD})$ & $11.3(3.2)$ & $10.1(3.6)$ & 0.01 \\
\hline \multicolumn{4}{|l|}{ Level of education; $n(\%)$} \\
\hline No formal education (0 year) & $0(0.0)$ & $3(2.0)$ & \multirow{4}{*}{0.01} \\
\hline Primary education (1-6 years) & $34(16.0)$ & $31(20.3)$ & \\
\hline Secondary education (7-10 years) & $55(25.8)$ & $60(39.2)$ & \\
\hline Tertiary education ( $\geq 11$ years) & $124(58.2)$ & $59(38.6)$ & \\
\hline \multicolumn{4}{|l|}{ Clinical assessments; $M(\mathrm{SD})$} \\
\hline CDR-SB & $0.0(0.0)$ & $4(3.6)$ & $<0.001$ \\
\hline MMSE-P & $27.9(1.6)$ & $19.5(7.4)$ & $<0.001$ \\
\hline MoCA-P & $24.4(2.4)$ & $11.9(6.3)$ & $<0.001$ \\
\hline Lawton's IADL & $8.7(1.7)$ & $16.7(7.6)$ & $<0.001$ \\
\hline
\end{tabular}

AD8-P: Filipino version of AD8; CDR-SB: Clinical Dementia Rating Scale-Sum of Boxes; MMSE-P: Filipino-validated Mini-Mental State Examination (MMSE-P); MoCA-P: Filipino-validated Montreal Cognitive Assessment; Lawton's IADL: Lawton's Instrumental Activities of Daily Living; M: mean; SD: standard deviation; $n$ : frequency.

relationship the informant has with the older person. However, gender of the informant, particularly being female, was associated with significantly higher AD8-P score. This may be because women are usually the caregivers and more aware of the subtle changes in the older persons' cognitive function. Nonetheless, excellent overall predictive ability of the AD8-P was not affected by the gender of the informants, since the AUROC was comparable for both male and female informants.

Majority of the dementia cases (90\%) in this study was in the earliest stages of dementia (very mild to mild). The distribution of dementia stages among the cases 
TABLE 2: Comparison between the groups of older persons with normal cognition and dementia for each item of the AD8-P.

\begin{tabular}{|c|c|c|c|}
\hline AD8-P questions (reported yes by informants) & $\begin{array}{c}\text { Normal }(n=213) \\
n(\%)\end{array}$ & $\begin{array}{c}\text { Dementia }(\mathrm{n}=153) \\
n(\%)\end{array}$ & $p$ value \\
\hline Item 1: problems with judgment & $28(13.1)$ & $96(62.7)$ & $<0.001$ \\
\hline Item 2: reduced interests and hobbies & $46(21.6)$ & $105(68.6)$ & $<0.001$ \\
\hline Item 3: repetition & $36(16.9)$ & $83(54.6)$ & $<0.001$ \\
\hline Item 4: use of appliances or devices & $72(33.8)$ & $134(88.2)$ & $<0.001$ \\
\hline Item 5: temporal orientation & $39(18.3)$ & $116(75.8)$ & $<0.001$ \\
\hline Item 6: handling finances & $7(3.3)$ & $90(58.8)$ & $<0.001$ \\
\hline Item 7: remembering appointments & $29(13.6)$ & $96(62.7)$ & $<0.001$ \\
\hline Item 8: consistent memory problems & $56(26.3)$ & $113(74.3)$ & $<0.001$ \\
\hline
\end{tabular}

AD8-P: Filipino version of the AD8; $n$ : frequency.

TABLE 3: Correlation of AD8-P scores with other cognitive and functional assessments.

\begin{tabular}{lcc}
\hline Clinical assessments & Correlation coefficients & $p$ value \\
\hline CDR-SB & 0.60 & $<0.001$ \\
MMSE-P & -0.60 & $<0.001$ \\
MoCA-P & -0.71 & $<0.001$ \\
Lawton's IADL & 0.61 & $<0.001$ \\
\hline
\end{tabular}

AD8-P: Filipino version of AD8; CDR-SB: Clinical Dementia Rating ScaleSum of Boxes; MMSE-P: Filipino-validated Mini-Mental State Examination (MMSE-P); MoCA-P: Filipino-validated Montreal Cognitive Assessment; Lawton's IADL: Lawton's Instrumental Activities of Daily Living.

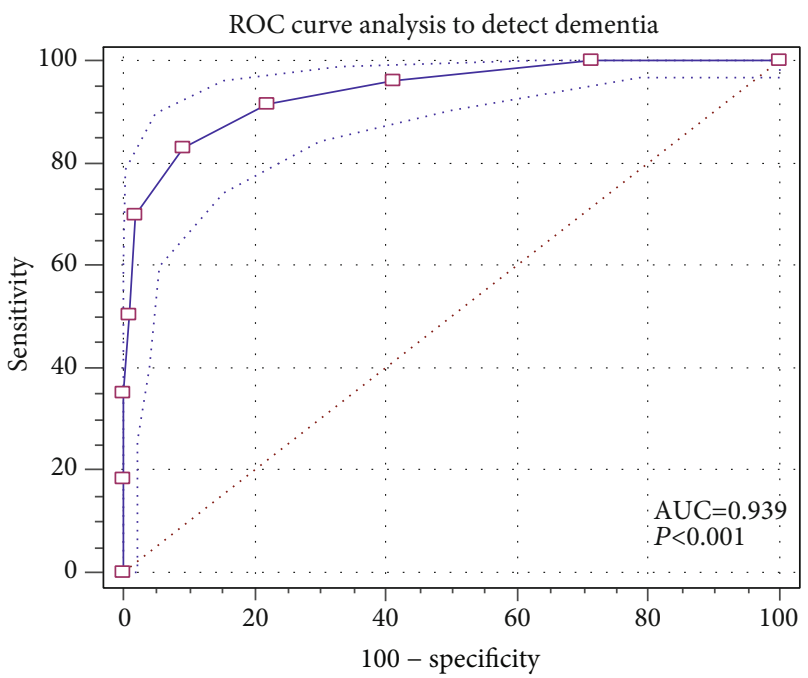

FIgURE 1: Receiver operating curve (ROC) of AD8-P to detect dementia.

identified for this validation study reflects the spectrum of dementia severity detected by dementia screening in the community, as we screened an entire community-based cohort for case finding. Thus, AD8-P is a very good instrument for early detection of dementia in the community. It is simple and brief, does not require much training, and is well accepted by informants. The results of this validation study have shown that AD8-P is particu- larly suitable to be used by frontline community health workers and primary care health professionals to screen for dementia in the Philippines.

We recognize the spectrum of cognitive impairment spanning from normal aging to subjective cognitive impairment to mild cognitive impairment and eventually dementia diagnosis; however, one limitation of our study is that we only analyzed the two ends of the spectrum: cognitively normal individuals and patients living with dementia. The authors plan to do a longitudinal study to follow up our cohort and include in the analysis all the clinical stages of cognitive impairment. Another possible limitation is that while frontotemporal dementia (FTD) has been studied in the context of other dementias, future studies could specifically examine the properties of the AD8 in FTD.

The optimum cut-off points for AD8-P in this study are between 3 and 4, which is higher than the recommended cut-off point $\geq 2$ in the original English version of the AD8 used in the US [20, 21], which was subsequently supported through validation studies in industrialized Asian countries such as Japan, Taiwan, and South Korea with fairly well-educated study population [28-30]. However, in a Brazilian study population with lower education and mixed ethnicities, they found the same cut-off point of $\geq 3$ as in our study [31]. The reasons given for higher cut-off point were lower education and lower socioeconomic status. It is out of context to ask the older persons if they can learn how to operate high-tech electronics and gadgets when these items are not available in their homes. The same reason may apply to the Philippines, a low middle-income country where about one-quarter of the population live in poverty and modern appliances such as microwave and computer are not common items in many households. As we can see in Table 2, informants reported problems with using appliances and devices for about one-third of the cognitively intact older persons. Nevertheless, in other industrialized countries such as Singapore and Spain, they also found the same cut-off point of $\geq 3[32,33]$. Regardless of cut-off points, the sensitivity and specificity reported for AD8 in other countries are comparable to our current findings, demonstrating its universal validity to screen for dementia across cultures and 
TABLE 4: Psychometric properties of AD8-P at different cut-off points.

\begin{tabular}{|c|c|c|c|c|c|c|}
\hline Cut-off & Sensitivity & Specificity & Youden index & PPV & NPV & Correctly identified \\
\hline$\geq 2$ points & $\begin{array}{c}96.1 \\
(0.91-0.98)\end{array}$ & $\begin{array}{c}42.1 \\
(0.34-0.50)\end{array}$ & 0.38 & $\begin{array}{c}62.6 \\
(0.56-0.69)\end{array}$ & $\begin{array}{c}91.4 \\
(0.82-0.96)\end{array}$ & $\begin{array}{c}57.7 \\
(0.53-0.63)\end{array}$ \\
\hline$\geq 3$ points & $\begin{array}{c}91.5 \\
(0.85-0.95)\end{array}$ & $\begin{array}{c}77.9 \\
(0.72-0.83)\end{array}$ & 0.69 & $\begin{array}{c}74.9 \\
(0.68-0.81)\end{array}$ & $\begin{array}{c}92.7 \\
(0.87-0.96)\end{array}$ & $\begin{array}{c}83.6 \\
(0.79-0.87)\end{array}$ \\
\hline$\geq 4$ points & $\begin{array}{c}83.0 \\
(0.76-0.88)\end{array}$ & $\begin{array}{c}90.6 \\
(0.86-0.94)\end{array}$ & 0.74 & $\begin{array}{c}86.4 \\
(0.86-0.80)\end{array}$ & $\begin{array}{c}88.1 \\
(0.83-0.92)\end{array}$ & $\begin{array}{c}87.4 \\
(0.84-0.91)\end{array}$ \\
\hline
\end{tabular}

All values except Youden's index are percentages with $95 \%$ confidence interval in parentheses. PPV: positive predictive value; NPV: negative predictive value; AD8-P: Filipino version of the AD8.

TABLE 5: Comparisons of mean AD8-P scores stratified by the older persons' and informants' characteristics.

\begin{tabular}{|c|c|c|}
\hline Participants' characteristics & $\begin{array}{c}\text { AD8-P scores } \\
M(\mathrm{SD})\end{array}$ & $p$ value \\
\hline \multicolumn{3}{|l|}{ Older persons' characteristics } \\
\hline \multicolumn{3}{|l|}{ Gender } \\
\hline Male & $1.7(1.5)$ & \multirow{2}{*}{0.16} \\
\hline Female & $1.4(1.3)$ & \\
\hline \multicolumn{3}{|l|}{ Age groups } \\
\hline 60-69 years old & $1.3(1.2)$ & \multirow{3}{*}{0.12} \\
\hline 70-79 years old & $1.7(1.4)$ & \\
\hline$\geq 80$ years old & $1.7(1.5)$ & \\
\hline \multicolumn{3}{|l|}{ Education groups* } \\
\hline Primary education (1-6 years) & $1.4(1.4)$ & \multirow{3}{*}{0.36} \\
\hline Secondary education (7-10 years) & $1.4(1.3)$ & \\
\hline Tertiary education ( $\geq 11$ years) & $1.8(1.4)$ & \\
\hline \multicolumn{3}{|l|}{ Informants' characteristics } \\
\hline \multicolumn{3}{|l|}{ Gender } \\
\hline Male & $1.0(1.0)$ & \multirow{2}{*}{0.001} \\
\hline Female & $1.7(1.5)$ & \\
\hline \multicolumn{3}{|l|}{ Relationship to the older person } \\
\hline Spouse & $1.7(1.4)$ & \multirow{4}{*}{0.25} \\
\hline Child & $1.2(1.3)$ & \\
\hline Grandchild & $1.4(1.1)$ & \\
\hline Others & $1.4(1.4)$ & \\
\hline \multicolumn{3}{|l|}{ Age groups } \\
\hline 18-24 years old (young adult) & $1.2(1.5)$ & \multirow{3}{*}{0.35} \\
\hline 25-64 years old (mid-adult) & $1.3(1.3)$ & \\
\hline$\geq 65$ years old (older adult) & $1.6(1.4)$ & \\
\hline \multicolumn{3}{|l|}{ Education groups* } \\
\hline Primary education (1-6 years) & $1.3(1.2)$ & \multirow{3}{*}{0.71} \\
\hline Secondary education (7-10 years) & $1.4(1.1)$ & \\
\hline Tertiary education ( $\geq 11$ years) & $1.5(1.6)$ & \\
\hline
\end{tabular}

${ }^{*}$ No formal education was not included in the analysis because it has fewer than two cases for group with normal cognition. AD8-P: Filipino version of the AD8; $M$ : mean; SD: standard deviation.

languages. However, it is recommended to validate AD8 in the specific language and culture to identify the optimal cut-off point for that specific population.

\section{Conclusion}

In conclusion, the AD8-P is a valid brief screening tool for dementia in the community. It can be recommended for widespread use to facilitate early detection of dementia in the Philippines.

\section{Data Availability}

The technical appendix, statistical code, and dataset used to support the findings in this study will be made available from the corresponding author upon request.

\section{Conflicts of Interest}

The authors declare no conflict of interest.

\section{Acknowledgments}

The authors thank the study participants and their families, the officials, and community health workers from the Office of the Senior Citizen Affairs (OSCA) of the Marikina City for their valuable time and participation in the study. The authors acknowledge Dr. Simeon Marasigan for his contribution in the conceptualization of this study and the translation and adaptation of AD8 into Filipino. With his untimely demise, we pay tribute to his vigor and tireless efforts to make dementia diagnosis accessible to elderly Filipinos by education of health professional about dementia through the Dementia Society of the Philippines (DSP) which he founded. His life continues to inspire the DSP and young neurologist to pursue training in dementia. To him we dedicate this manuscript. The Eight-item Interview to Differentiate Aging and Dementia, also referred to as the $\mathrm{AD}^{\circledR}{ }^{\circledR}$, is a copyrighted and trademarked instrument of the Washington University, St. Louis, Missouri, USA, Copyright $\odot 2005$ Washington University, St. Louis, Missouri. All Rights Reserved. This study was supported by grants from the Philippine Council for Health Research and Development of the Department of Science and Technology (FP-150011) and St. Luke's Medical Center (15-002).

\section{References}

[1] M. J. Prince, A. Wimo, M. M. Guerchet, G. C. Ali, Y.-T. Wu, and M. Prina, World Alzheimer Report 2015: the global impact 
of dementia, Alzheimer's Disease International, London, UK, 2015.

[2] J. Dominguez, M. Fe de Guzman, M. Reandelar, and T. K. Thi Phung, "Prevalence of dementia and associated risk factors: a population-based study in the Philippines," Journal of Alzheimer's Disease, vol. 63, no. 3, pp. 1065-1073, 2018.

[3] L. Lang, A. Clifford, L. Wei et al., "Prevalence and determinants of undetected dementia in the community: a systematic literature review and a meta-analysis," BMJ Open, vol. 7, no. 2, pp. e011146-e011148, 2017.

[4] A. Bradford, M. E. Kunik, P. Schulz, S. P. Williams, and H. Singh, "Missed and delayed diagnosis of dementia in primary care: prevalence and contributing factors," Alzheimer Disease and Associated Disorders, vol. 23, no. 4, pp. 306-314, 2009.

[5] A. D. Ligsay, Validation of the Mini Mental State Examination in the Philippines, University of the Philippines, Manila, 2003.

[6] J. C. Dominguez, J. R. Soriano, C. D. Magpantay et al., "Early detection of mild Alzheimer's disease in Filipino elderly: validation of the Montreal cognitive Assessment-Philippines (MoCA-P)," Advances in Alzheimer's Disease, vol. 3, no. 4, pp. 160-167, 2014.

[7] J. C. Dominguez, M. G. S. Orquiza, J. R. Soriano et al., "Adaptation of the Montreal Cognitive Assessment for elderly Filipino patients," East Asian Archives of Psychiatry, vol. 23, no. 3, pp. 80-85, 2013.

[8] S. Freitas, M. R. Simoes, L. Alves, and I. Santana, "Montreal Cognitive Assessment: influence of sociodemographic and health variables," Archives of Clinical Neuropsychology, vol. 27, no. 2, pp. 165-175, 2012.

[9] R. F. Uhlmann and E. B. Larson, "Effect of education on the mini-mental state examination as a screening test for dementia," Journal of the American Geriatrics Society, vol. 39, no. 9, pp. 876-880, 1991.

[10] T. R. Nielsen, T. K. T. Phung, M. Chaaya, A. Mackinnon, G. Waldemar, and G. Waldemar, "Combining the Rowland universal dementia assessment scale and the informant questionnaire on cognitive decline in the elderly to improve detection of dementia in an Arabic-speaking population," Dementia and Geriatric Cognitive Disorders, vol. 41, no. 1-2, pp. 46-54, 2016.

[11] K. Narasimhalu, J. Lee, A. P. Auchus, and C. P. L. H. Chen, "Improving detection of dementia in Asian patients with low education : combining the mini-mental state examination and the informant questionnaire on cognitive decline in the elderly," Dementia and Geriatric Cognitive Disorders, vol. 25, no. 1, pp. 17-22, 2007.

[12] J. E. Galvin, "Using informant and performance screening methods to detect mild cognitive impairment and dementia," Current Geriatrics Reports, vol. 7, no. 1, pp. 19-25, 2018.

[13] M. C. Tierney, N. Herrmann, D. M. Geslani, and J. P. Szalai, "Contribution of informant and patient ratings to the accuracy of the mini-mental state examination in predicting probable Alzheimer's disease," Journal of the American Geriatrics Society, vol. 51, no. 6, pp. 813-818, 2003.

[14] A. Jorm, "A short form of the informant questionnaire on cognitive decline in the elderly (IQCODE): development and cross-validation," Psychological Medicine, vol. 24, no. 1, pp. 145-153, 1994.

[15] J. C. Morris, "The clinical dementia rating (CDR): current version and scoring rules," Neurology, vol. 43, no. 11, pp. 24122414, 1993.
[16] J. C. Morris, D. W. McKeel, M. Storandt et al., "Very mild Alzheimer's disease informant-based clinical, psychometric, and pathologic distinction from normal aging," Neurology, vol. 41, no. 4, pp. 469-478, 1991.

[17] K. T. T. Phung, M. Chaaya, K. Asmar et al., "Performance of the 16-item informant questionnaire on cognitive decline for the elderly (IQCODE) in an Arabic-speaking older population," Dementia and Geriatric Cognitive Disorders, vol. 40, no. 5-6, pp. 276-289, 2015.

[18] J. L. Fuh, E. L. Teng, K. N. Lin et al., “The informant questionnaire on cognitive decline in the elderly (IQCODE) as a screening tool for dementia for a predominantly illiterate Chinese population," Neurology, vol. 45, no. 1, pp. 92-96, 1995.

[19] M. Razavi, M. I. Tolea, J. Margrett et al., "Comparison of 2 informant questionnaire screening tools for dementia and mild cognitive Impairment," Alzheimer Disease and Associated Disorders, vol. 28, no. 2, pp. 156-161, 2014.

[20] J. E. Galvin, C. M. Roe, K. K. Powlishta et al., "The AD8: a brief informant interview to detect dementia," Neurology, vol. 65, no. 4, pp. 559-564, 2005.

[21] H. J. Ryu, H. J. Kim, S. H. Han, and J. C. Morris, "Validity and reliability of the AD8 informant interview in dementia," $\mathrm{Neu}$ rology, vol. 67, no. 11, pp. 1942-1948, 2006.

[22] J. E. Galvin, A. M. Fagan, D. M. Holtzman, M. A. Mintun, and J. C. Morris, "Relationship of dementia screening tests with biomarkers of Alzheimer's disease," Brain, vol. 133, no. 11, pp. 3290-3300, 2010.

[23] G. M. Morris, T. R. Holden, H. Weng et al., "Comparative performance and neuropathologic validation of the AD8 dementia screening instrument," Alzheimer Disease and Associated Disorders, vol. 34, no. 2, pp. 112-117, 2020.

[24] J. E. Galvin, C. M. Roe, M. A. Coats, and J. C. Morris, "Patient's rating of cognitive ability: using the $\mathrm{AD} 8$, a brief informant interview as a self-rating tool to detect dementia," Archives of Neurology, vol. 64, no. 5, pp. 725-730, 2007.

[25] American Psychiatric Association, Diagnostic and Statistical Manual of Mental Disorders - Fourth Edition, Text Revision (DSM-IV TR), American Psychiatric Association, Washington: USA, 4th ed. edition, 2000.

[26] M. P. Lawton and E. M. Brody, "Assessment of older people: self-maintaining and instrumental activities of daily living," The Gerontologist, vol. 9, 3 Part 1, pp. 179-186, 1969.

[27] J. A. Yesavage and J. I. Sheikh, "Geriatric depression scale (GDS)," Clinical Gerontologist, vol. 5, pp. 165-173, 2008.

[28] K. Meguro, M. Kasai, and K. Nakamura, "Reliability and validity of the Japanese version of the AD8," Japanese Journal of Geriatrics, vol. 52, pp. 61-70, 2015.

[29] Y. H. Yang, J. E. Galvin, J. C. Morris, C. L. Lai, M. C. Chou, and C. K. Liu, "Application of AD8 questionnaire to screen very mild dementia in Taiwanese," American Journal of Alzheimer's Disease and Other Dementias, vol. 26, no. 2, pp. 134-138, 2011.

[30] H. J. Ryu, H. Kim, and S. Han, "Validity and reliability of the Korean version of the AD8 Informant Interview (K-AD8) in Dementia," Alzheimer Disease and Associated Disorders, vol. 23, no. 4, pp. 371-376, 2009.

[31] C. C. Correia, F. Lima, F. Junqueira et al., "AD8-Brazil: crosscultural validation of the ascertaining dementia interview in Portuguese," Journal of Alzheimer's Disease, vol. 27, no. 1, pp. 177-185, 2011. 
[32] C. Carnero Pardo, R. de la Vega Cotarelo, S. López Alcalde et al., "Evaluacion de la utilidad diagnostica de la version española del cuestionario al informador «AD8»," Neurología, vol. 28, no. 2, pp. 88-94, 2013.

[33] Q. L. Chan, X. Xu, M. A. Shaik et al., "Clinical utility of the informant AD8 as a dementia case finding instrument in primary healthcare," Journal of Alzheimer's Disease, vol. 49, no. 1, pp. 121-127, 2015. 